\title{
Initial Noninvasive Oxygenation Strategies in Subjects With De Novo Acute Hypoxemic Respiratory Failure
}

\author{
Yazan Zayed, Mahmoud Barbarawi, Babikir Kheiri, Tarek Haykal, Adam Chahine, Laith Rashdan, \\ Harsukh Dhillon, Sina Khaneki, Ghassan Bachuwa, and Elfateh Seedahmed
}

\begin{abstract}
BACKGROUND: De novo hypoxemic respiratory failure is defined as significant hypoxemia in the absence of chronic lung disease such as COPD, and excluding respiratory failure occurring in the immediate postoperative or postextubation period. We aimed to evaluate the efficacy of various oxygenation strategies including noninvasive ventilation (NIV), high-flow nasal cannula (HFNC), and conventional oxygen therapy in patients with de novo hypoxemic respiratory failure. METHODS: We performed electronic database searches of PubMed, Cochrane Library, and Embase from inception to December 2018 to include randomized controlled trials that compared various oxygenation strategies in cases of de novo hypoxemic respiratory failure occurring in adult subjects without a preexisting chronic lung disease and excluding respiratory failure in the immediate postoperative or postextubation periods. We performed a Bayesian network meta-analysis to calculate odds ratio $(\mathrm{OR})$ and Bayesian 95\% credible intervals (CrI). RESULTS: 16 studies were included, involving 2,180 subjects with a mean age of $61 \pm 17$ y $(66 \%$ were male; $46 \%$ of the included subjects were treated with conventional oxygen, $27.8 \%$ were treated with NIV, and $25.8 \%$ were treated with HFNC). Compared to conventional oxygen, NIV was associated with reduced intubation rates (OR 0.42, 95\% CrI 0.26-0.62) but no significant reduction in short-term (OR 0.73, 95\% CrI 0.47-1.02) or long-term mortality (OR 0.60, 95\% CrI 0.29-1.06). There was no significant difference between NIV and HFNC or between HFNC and conventional oxygen regarding all outcomes. In a sensitivity analysis, the results remained consistent after exclusion of studies that included subjects with respiratory failure secondary to cardiogenic pulmonary edema. CONCLUSION: Among subjects with hypoxemic respiratory failure, NIV was associated with a significant reduction in intubation rates but not short- or long-term mortality when compared to conventional oxygen therapy. There was no significant difference between NIV and HFNC or between HFNC and conventional oxygen regarding all outcomes. Key words: high-flow nasal cannula; noninvasive ventilation; de novo respiratory failure; meta-analysis; network; hypoxemic respiratory failure; conventional oxygen. [Respir Care 2019;64(11):1433-1444. (C) 2019 Daedalus Enterprises]
\end{abstract}

Introduction

De novo hypoxemic respiratory failure is defined as significant hypoxemia $\left(\mathrm{P}_{\mathrm{aO}_{2}} / \mathrm{F}_{\mathrm{IO}_{2}} \leq 300 \mathrm{~mm} \mathrm{Hg}\right)$ with tachy-

Drs Zayed, Barbarawi, Kheiri, Haykal, Chahine, Rashdan, Dhillon, Khaneki, and Bachuwa are affiliated with the Department of Internal Medicine, and Dr Seedahmed is affiliated with the Department of Pulmonary and Critical Care, Hurley Medical Center/Michigan State University, Flint, Michigan.

The authors have disclosed no conflicts of interest. pnea and other signs of respiratory distress in the absence of chronic lung disease such as COPD and excluding respiratory failure occurring in the immediate postoperative or postextubation period. ${ }^{1}$ The use of noninvasive venti-

Supplementary material related to this paper is available at http:// www.rcjournal.com.

Correspondence: Yazan Zayed MD, Department of Internal Medicine, Hurley Medical Center/Michigan State University, One Hurley Plaza, Suite 212, Flint, MI 48503. E-mail: yzayed1@hurleymc.com.

DOI: $10.4187 /$ respcare.06981 
lation (NIV) has been associated with a reduction in intubation rates for patients with exacerbations of COPD and cardiogenic pulmonary edema. ${ }^{2-4}$ Additionally, NIV has been recommended by the current European Respiratory Society/American Thoracic Society (ERS/ATS) guidelines in patients with COPD and cardiogenic pulmonary edema. ${ }^{1}$ However, the use of NIV in patients with postoperative respiratory failure, trauma patients, and as prophylaxis for respiratory failure in high-risk populations after extubation are conditional and are largely dependent on the overall context. ${ }^{1}$

Nevertheless, in patients with de novo hypoxemic respiratory failure, ERS/ATS has no clear recommendation regarding use of NIV. ${ }^{1}$ Results of previous randomized controlled trials (RCTs) concerning NIV in non-hypercapnic acute hypoxemic respiratory failure have been conflicting. ${ }^{5-8}$ Several meta-analyses showed significant reduction in rates of intubation and mortality with NIV usage. ${ }^{9,10}$

Recently, high-flow nasal cannula (HFNC) therapy has been used more frequently in the treatment of acute hypoxemic respiratory failure. ${ }^{11}$ In a large RCT, Frat et $\mathrm{al}^{5}$ reported that HFNC was associated with a reduction in 90-d mortality when compared to NIV and conventional oxygen therapy in subjects with acute hypoxemic respiratory failure. However, further subsequent trials and metaanalyses showed no difference between HFNC and conventional oxygen therapy ${ }^{12-17}$ or NIV. ${ }^{18,19}$

In light of these controversies and the lack of head-tohead studies comparing HFNC and NIV, we conducted a network meta-analysis comparing the 3 initial oxygenation strategies (NIV vs HFNC vs conventional oxygen therapy) in subjects with de novo acute hypoxemic respiratory failure.

\section{Methods}

\section{Study Design and Data Source}

Our study was a systematic review and network metaanalysis of RCTs conducted according to the Preferred Reporting Items for Systematic Reviews and Meta-Analyses Protocols 2015 Statement. ${ }^{20}$ An electronic database search was performed utilizing the PubMed, Embase, and the Cochrane Library databases from inception until December 2018 without language restrictions. Two reviewers (BK, MB) independently and separately performed literature searches, and any discrepancy was resolved with consensus with a third reviewer (YZ). Articles were first screened by abstract and title, and the full text of eligible articles were reviewed before exclusion. The following $\mathrm{MeSH}$ terms were used: hypoxemic respiratory failure, hypoxemic respiratory failure, de novo respiratory failure, respiratory failure, acute respiratory failure, noninvasive ventilation, high-flow nasal cannula, NIV, HFNC, and oxygen. In addition, we reviewed the references of relevant articles and performed a manual internet search for possible inclusion.

\section{Study Selection}

Our study included only RCTs that compared HFNC, NIV, and conventional oxygen therapy in subjects with hypoxemic respiratory failure, defined by having at least one of the following criteria: $\mathrm{P}_{\mathrm{aO}_{2}} / \mathrm{F}_{\mathrm{IO}_{2}} \leq 300, \mathrm{P}_{\mathrm{aO}_{2}} \leq$ $65 \mathrm{~mm} \mathrm{Hg}, \mathrm{S}_{\mathrm{pO}_{2}} \leq 92 \%$ with signs and symptoms of respiratory distress. Patients with chronic lung diseases or who developed respiratory failure in the immediate postoperative or postextubation period were excluded. We excluded RCTs that exclusively enrolled subjects with COPD, cardiogenic pulmonary edema, or postextubation respiratory failure. In studies that included different patient populations and provided results for outcomes of interest based on the reason of acute respiratory failure, we extracted outcomes for subjects with de novo hypoxemic respiratory failure that met our inclusion criteria. In studies that included a proportion of subjects with pulmonary edema as a cause for hypoxemic respiratory failure without reporting data for specific patient populations, we opted to include these studies in the primary analysis; however, they were removed in a sensitivity analysis.

Data were extracted by two reviewers (LR, HD) into a predesigned table, and any discrepancies was solved by a consensus with a third reviewer (YZ).

\section{Outcomes}

The primary outcome was intubation rates and the need for invasive mechanical ventilation. Secondary outcomes included short-term mortality (ie, during ICU length of stay or $\leq 28 \mathrm{~d}$ ) and long-term mortality (defined as hospital mortality or mortality at the longest follow-up period provided by each study).

\section{Quality Assessment}

Quality assessment was performed independently and separately by two reviewers (BK, MB) using the Cochrane collaboration tool to evaluate risk of bias for random sequence generation, allocation concealment, blindness of participants and health care personnel, blindness of outcome assessment, incomplete outcome data, selective reporting, and other biases in each of included studies in each of the included studies. Any discrepancy was resolved with consensus with a third reviewer (YZ). 


\section{Statistical Analysis}

A Bayesian framework for the network meta-analysis was performed using the Markov Chain Monte Carlo simulation to derive the posterior distribution of the parameter estimates. We used the Brooks-Gelman-Rubin method to assess convergence. A random effects model for consistency was utilized to account for the population heterogeneity. Data were reported as odds ratios (ORs) and Bayesian $95 \%$ credible intervals (CrIs). Inconsistency was assessed using the deviance residuals and deviance information criteria statistics.

In an exploratory analysis, we performed a meta-regression analysis to explain any significant heterogeneity for direct meta-analysis. Moderators included study-level covariates: age, Simplified Acute Physiology Score II, breathing frequency, $\mathrm{P}_{\mathrm{aO}_{2}} / \mathrm{F}_{\mathrm{IO}_{2}}$ ratio, and $\mathrm{P}_{\mathrm{aCO}}$. Furthermore, a sensitivity analysis was performed for all outcomes by excluding studies that included subjects with respiratory failure secondary to pulmonary edema.

\section{Results}

\section{Included Studies and Study Population}

After reviewing 5,081 studies, 16 studies met our inclusion criteria and were included in the final analysis. Our search process is illustrated in Figure 1. Two trials compared HFNC versus conventional oxygen therapy, ${ }^{12,17}$ 12 trials compared NIV versus conventional oxygen therapy, 6-8,21-30 1 trial compared HFNC versus NIV, ${ }^{19}$ and 1 trial compared HFNC versus NIV versus conventional oxygen therapy. ${ }^{5}$ The network geometry showed that most studies compared NIV to conventional oxygen therapy; the next most frequent comparison was between HFNC and conventional oxygen therapy, and the least frequent comparison was HFNC versus NIV. Overall, conventional oxygen therapy was the most studied intervention, followed by NIV and then HFNC. Performance bias was noted in the included studies given the inherent difficulty in blinding a study to personnel and participants due to the nature of the intervention. Quality assessment results of the included studies, based on our judgment for each risk of bias, is illustrated in Figure 2. The characteristics of the included studies are shown in Table 1.

A total of 2,180 subjects were included in our analysis with a mean age of $61 \pm 17$ y ( $66 \%$ were male); $46 \%$ of the included subjects were treated with conventional oxygen therapy, $27.8 \%$ were treated with NIV, and $25.8 \%$ were treated with HFNC. The baseline subject characteristics are explained in Table 2.

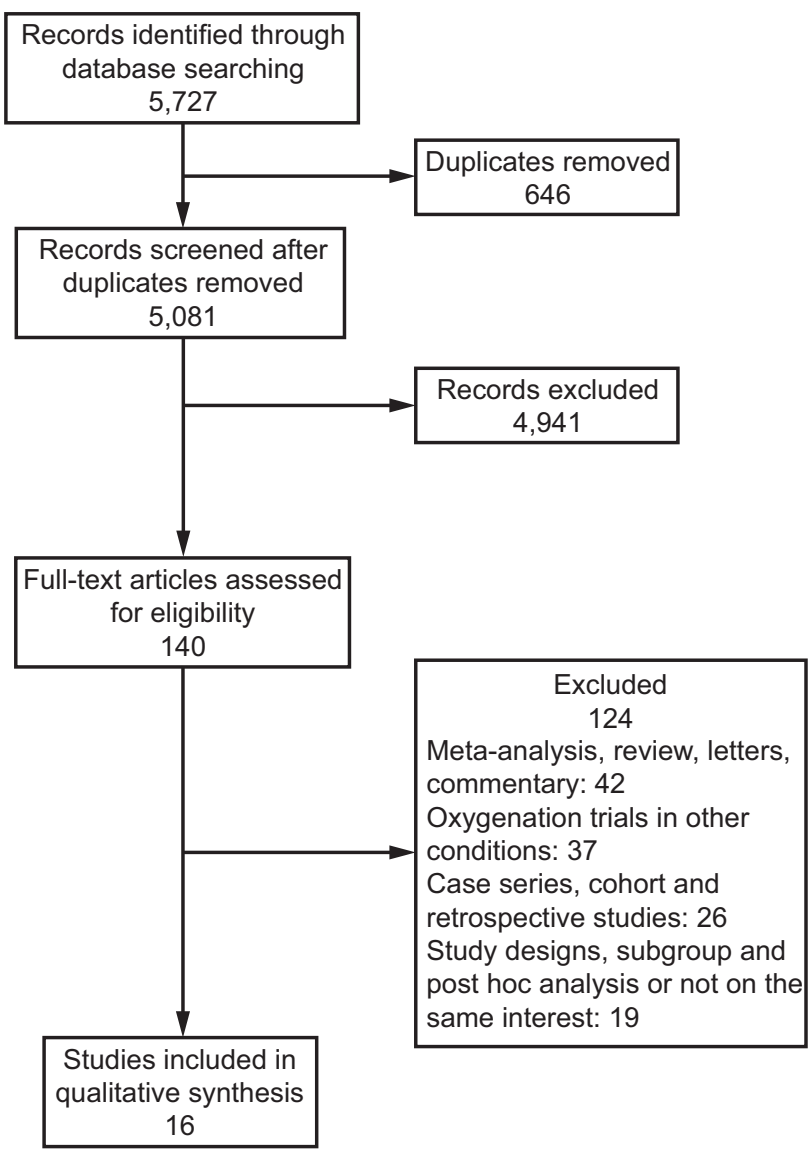

Fig. 1. Flow chart.

\section{Primary Outcome}

The rate of intubation and requirement for invasive mechanical ventilation was $39.4 \%$ in the total subject population (34\% in NIV, 36\% in HFNC, and $44 \%$ in the conventional oxygen therapy group). NIV was associated with a significant reduction in requirement for intubation and mechanical ventilation in comparison to conventional oxygen therapy (OR $0.42,95 \%$ CrI $0.26-0.62$ ). There were no significant differences between NIV and HFNC (OR 0.63, 95\% CrI 0.29-1.19) or HFNC and conventional oxygen therapy (OR $0.68,95 \%$ CrI $0.36-1.26$ ) (Fig. 3). In a subset analysis performed by excluding studies that included subjects with pulmonary edema, the results remained consistent (see the supplementary materials at http:// www.rcjournal.com). In an exploratory meta-regression analysis, there were no significant modifier effects of NIV on intubation rates based on trial-level covariates $(P>.05)$.

\section{Secondary Outcomes}

The incidence of short-term mortality in the total patient population included was $28.6 \%$. Although short-term mor- 


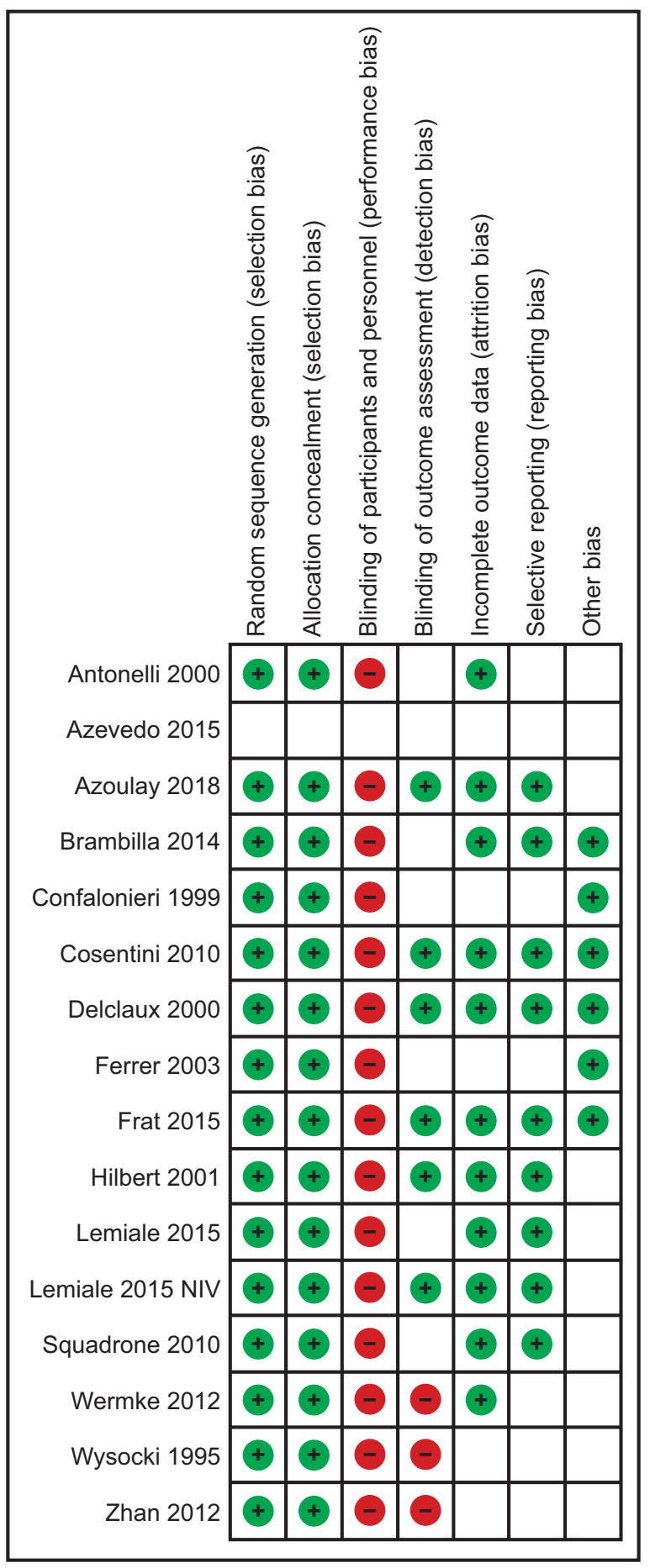

Fig. 2. Summary of risk of bias in the included studies based on the authors' judgments. Blank squares indicate unclear risk of bias.

tality rates were lower in NIV in comparison to conventional oxygen therapy ( $22 \%$ vs $31 \%$ ), the difference didn't reach statistical significance (OR $0.73,95 \%$ CrI $0.47-$ 1.02). Furthermore, there were no significant differences between NIV versus HFNC (OR 1.00, 95\% CrI $0.57-$
1.1.84) or HFNC versus conventional oxygen therapy (OR 0.73, 95\% CrI 0.39-1.15) (Fig. 4). Meta-regression analysis of the NIV effects on short-term mortality showed no modifier effects based on trial-level covariates $(P>.05)$.

With regard to long-term mortality, the incidence was $36 \%$. There was no significant reduction in long-term mortality between NIV and conventional oxygen therapy (OR 0.60, 95\% CrI 0.29-1.06), NIV versus HFNC (OR 1.02, 95\% CrI 0.39-2.63) or HFNC versus conventional oxygen therapy (OR $0.59,95 \%$ CrI $0.23-1.25$ ) (Fig. 5). Additionally, by performing a meta-regression analysis, we found an increased long-term mortality with advanced ages among NIV-treated patients compared with patients treated with conventional oxygen therapy $\left(\mathrm{R}^{2}=42 \% ; b=0.08\right.$; standard error $\left.=0.04, P=.04\right)($ see the supplementary materials at http://www.rcjournal.com). In a sensitivity analysis, results remained consistent for short-term and long-term mortality after excluding studies that included subjects with pulmonary edema (see the supplementary materials at http://www.rcjournal.com).

\section{Discussion}

In this first network meta-analysis evaluating the role of initial oxygenation strategies among patients with de novo respiratory failure, we observed that NIV was associated with decreased intubation rates in comparison to conventional oxygen therapy. Although rates of short- and longterm mortality were lower in the NIV group, the difference didn't reach statistical significance. However, there were no significant differences in the requirement for intubation, short- or long-term mortality between NIV and HFNC, or between HFNC and conventional oxygen therapy.

ERS/ATS guidelines have no clear recommendations regarding the use of NIV in patients with de novo respiratory failure, and the use of HFNC is not addressed in these guidelines. ${ }^{1}$ The physiological effects of NIV are largely attributed to improvements in gas exchange and reduction in work of breathing. ${ }^{1}$ NIV is often used in patients with de novo hypoxemic respiratory failure, which is often caused by community-acquired pneumonia and ARDS, to relieve respiratory distress and work of breathing and to avoid intubation and mechanical ventilation. ${ }^{1}$ However, the use of NIV has several limitations in these patients because it is less efficacious in relieving work load, such as in patients with COPD or cardiogenic pulmonary edema. Furthermore, increased tidal volume delivered with NIV increases transpulmonary pressure and can lead to further lung injury. ${ }^{31,32} \mathrm{HFNC}$ is a new oxygenation strategy that delivers $\mathrm{F}_{\mathrm{IO}_{2}}, 1.0$ at flows up to 60 $\mathrm{L} / \mathrm{min}$, which can overcome the high peak inspiratory flow during acute hypoxemic respiratory failure by generating a positive pressure. ${ }^{33,34}$ Furthermore, HFNC can deliver a 
Oxygenation in De Novo Acute Hypoxemic Respiratory Failure

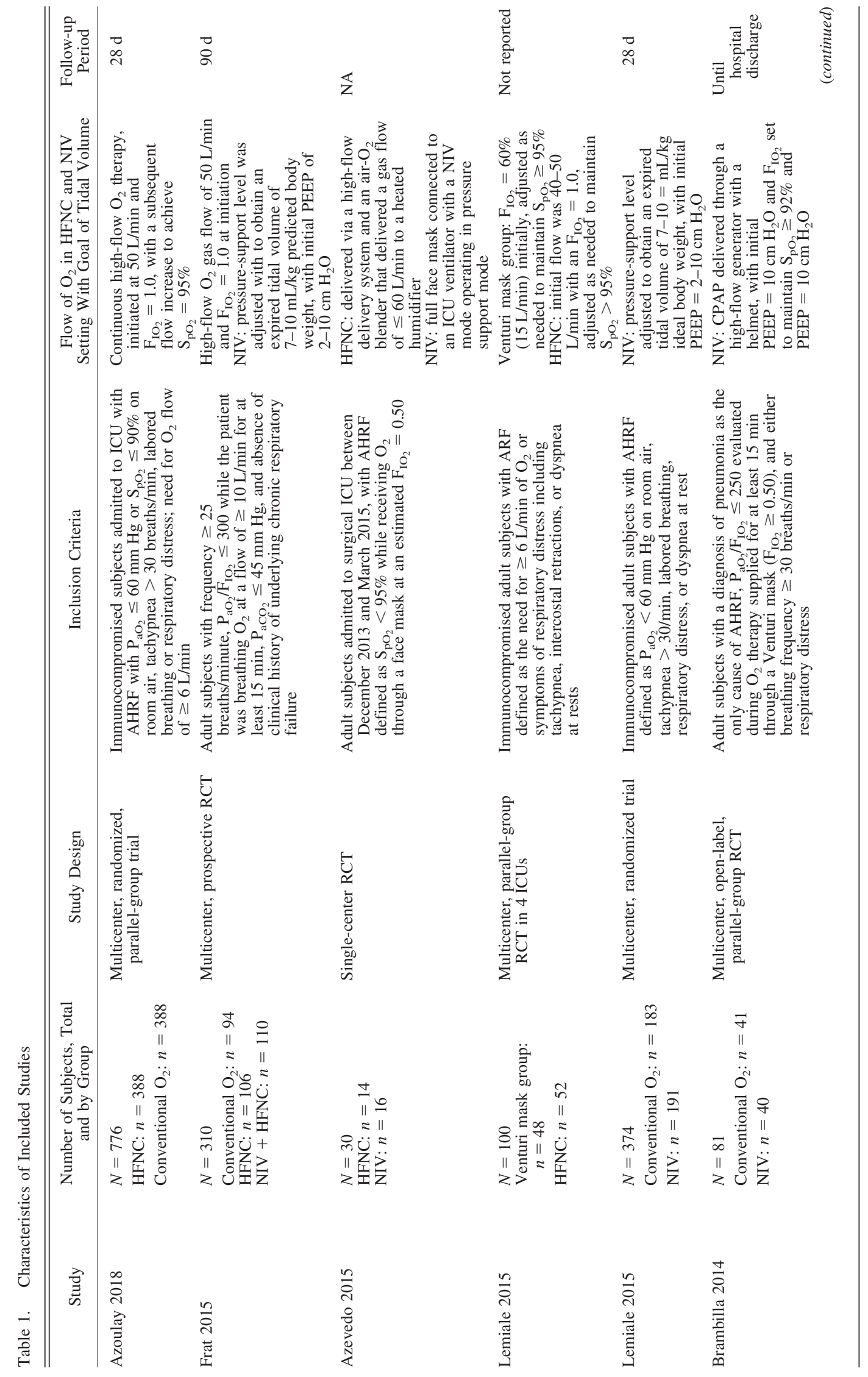


Oxygenation in De Novo Acute Hypoxemic Respiratory Failure

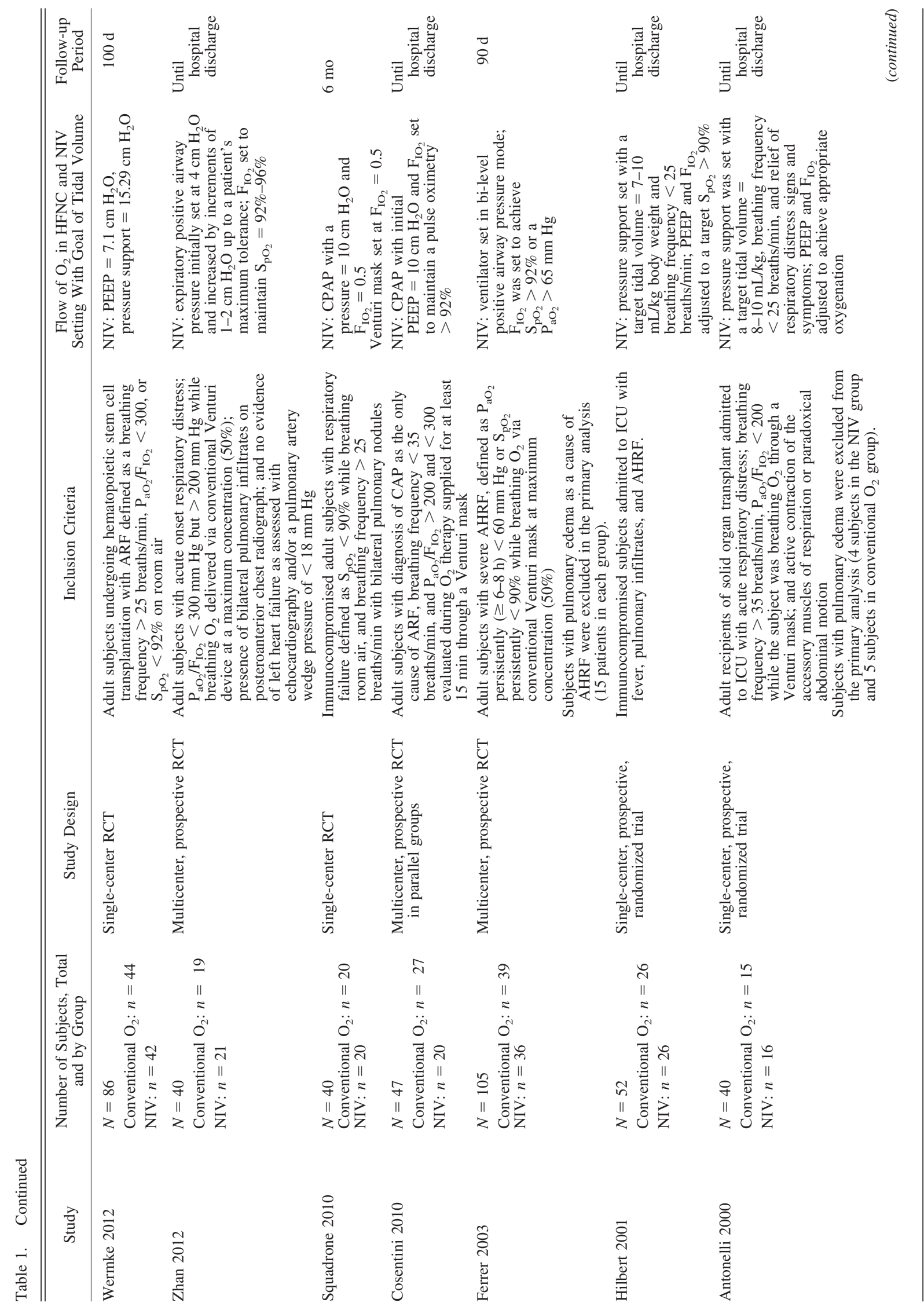


Oxygenation in De Novo Acute Hypoxemic Respiratory Failure

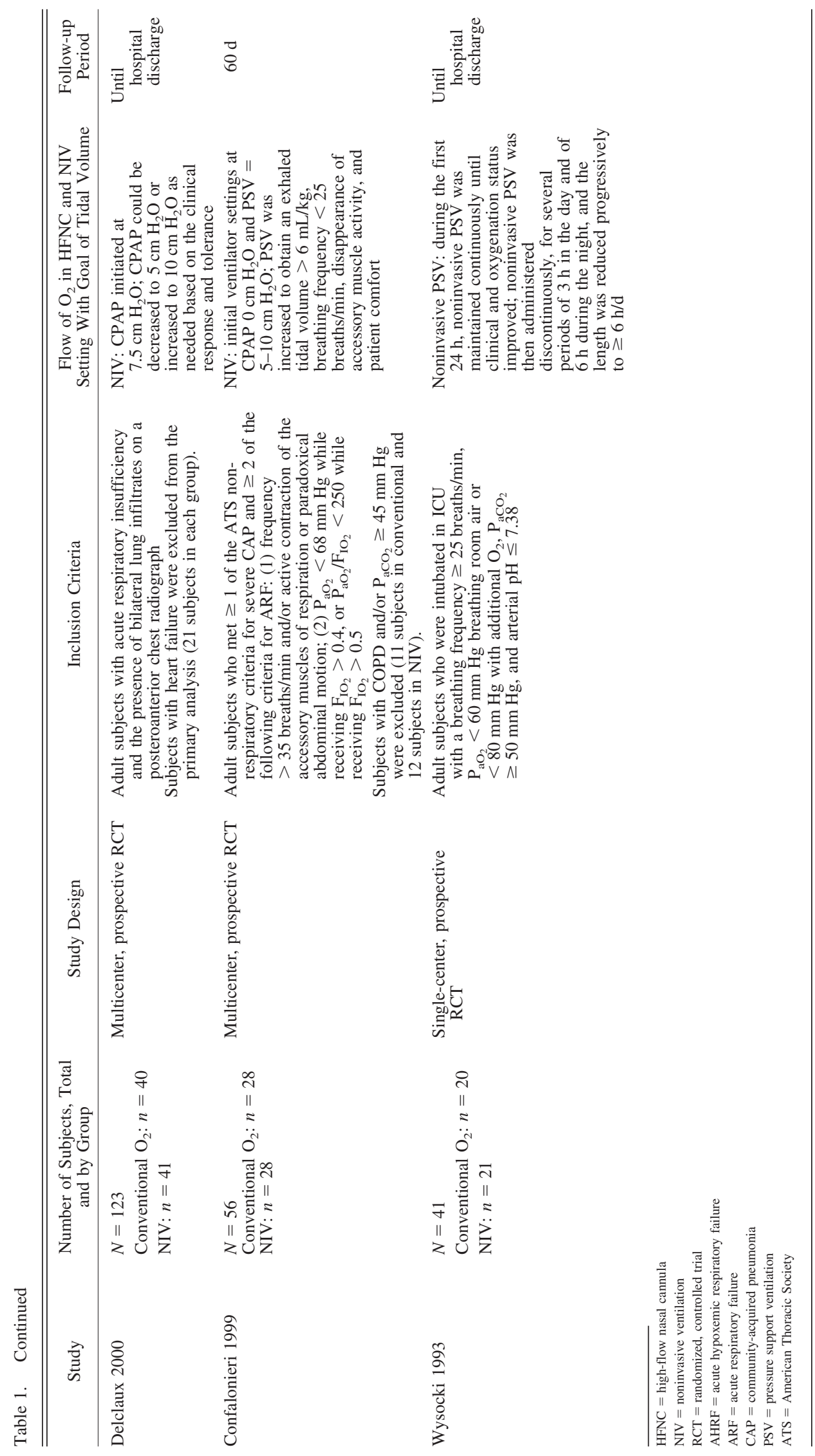


Table 2. Baseline Demographic and Clinical Characteristics of Subjects

\begin{tabular}{|c|c|c|c|c|c|c|c|c|c|}
\hline Study & Study Groups & $\begin{array}{l}\text { Subjects, } \\
\quad n\end{array}$ & Age, y & Male, $\%$ & $\begin{array}{l}\text { Hematological } \\
\text { and/or Solid } \\
\text { Malignancy, \% }\end{array}$ & $\begin{array}{l}\text { SAPS II } \\
\text { Score }\end{array}$ & $\begin{array}{l}\text { Frequency, } \\
\text { breaths/min }\end{array}$ & $\mathrm{P}_{\mathrm{aO}_{2}} / \mathrm{F}_{\mathrm{IO}_{2}}$ & $\mathrm{P}_{\mathrm{aCO}_{2}}$ \\
\hline \multirow[t]{2}{*}{ Azoulay 2018} & HFNC & 388 & $64(55-70)$ & 69.6 & 75.8 & $36(28-46)$ & $33(28-39)$ & $136(96-187)$ & NA \\
\hline & Conventional & 388 & $63(56-71)$ & 63.6 & 82.2 & $37(28-48)$ & $32(27-38)$ & $128(92-164)$ & NA \\
\hline \multirow[t]{3}{*}{ Frat 2015} & NIV & 110 & $61 \pm 17$ & 67 & 23.6 & $27 \pm 9$ & $33 \pm 7$ & $149 \pm 72$ & $34 \pm 6$ \\
\hline & HFNC & 106 & $61 \pm 16$ & 71 & 24.5 & $25 \pm 9$ & $33 \pm 6$ & $157 \pm 89$ & $36 \pm 6$ \\
\hline & Conventional & 94 & $59 \pm 17$ & 67 & 23 & $24 \pm 9$ & $32 \pm 6$ & $161 \pm 73$ & $35 \pm 5$ \\
\hline \multirow[t]{2}{*}{ Azevedo 2015} & HFNC & 14 & $61.4 \pm 13.7$ & 43 & NA & NA & NA & NA & NA \\
\hline & NIV & 16 & $72.3 \pm 19.0$ & 50 & NA & NA & NA & NA & NA \\
\hline \multirow[t]{2}{*}{ Lemiale 2015} & HFNC & 52 & $59.3(43-70)$ & 73.1 & 88.4 & $42(30-52)$ & $26(22-31)$ & $128(48-178)$ & NA \\
\hline & Conventional & 48 & $64.5(53-72)$ & 66.7 & 79.2 & $37.5(32-47)$ & $27(22-32)$ & $100(40-156)$ & NA \\
\hline \multirow[t]{2}{*}{ Lemiale 2015} & NIV & 191 & $61(52-70)$ & 61.3 & 84.8 & NA & $27(21-31)$ & $156(95-248)$ & NA \\
\hline & Conventional & 183 & $64(53-72)$ & 57.4 & 84.7 & NA & $25(21-30)$ & $130(86-205)$ & NA \\
\hline \multirow[t]{2}{*}{ Brambilla 2014} & NIV & 40 & $64.9 \pm 16.1$ & 60 & 22.5 & $34.7 \pm 7.6$ & $34.7 \pm 6.4$ & $134 \pm 32$ & $32.1 \pm 4.6$ \\
\hline & Conventional & 41 & $69.5 \pm 15.8$ & 70.7 & 29.3 & $35.8 \pm 9.9$ & $32.9 \pm 6.9$ & $148 \pm 44$ & $34.1 \pm 7.3$ \\
\hline \multirow[t]{2}{*}{ Wermke 2012} & NIV & 42 & NA & NA & 100 & NA & NA & NA & NA \\
\hline & Conventional & 44 & NA & NA & 100 & NA & NA & NA & NA \\
\hline \multirow[t]{2}{*}{ Zhan 2012} & NIV & 21 & $43.8 \pm 13.7$ & 76.2 & 0 & NA & $28.8 \pm 7.2$ & $225.4 \pm 17.4$ & $31.3 \pm 6.0$ \\
\hline & Conventional & 19 & $49.1 \pm 13.7$ & 42.1 & 5.3 & NA & $30.4 \pm 6.3$ & $234.4 \pm 26.6$ & $32.7 \pm 5.6$ \\
\hline \multirow[t]{2}{*}{ Squadrone 2010} & NIV & 20 & $49 \pm 14$ & 55 & 100 & $42 \pm 7$ & $29 \pm 5$ & $256 \pm 52$ & $41 \pm 3$ \\
\hline & Conventional & 20 & $49.5 \pm 14$ & 60 & 100 & $41.3 \pm 6$ & $30 \pm 4$ & $282 \pm 41$ & $42 \pm 3$ \\
\hline \multirow[t]{2}{*}{ Cosentini 2010} & NIV & 20 & $65 \pm 17$ & 70 & NA & $21 \pm 7.4$ & $27 \pm 4.5$ & $249 \pm 25$ & $34 \pm 6$ \\
\hline & Conventional & 27 & $72 \pm 13$ & 59 & NA & $21 \pm 5.7$ & $27 \pm 4.4$ & $246 \pm 20$ & $36 \pm 5$ \\
\hline \multirow[t]{2}{*}{ Ferrer 2003} & NIV & 36 & $61 \pm 17$ & 58 & NA & $34 \pm 10$ & $37 \pm 6$ & $102 \pm 21$ & $37 \pm 7$ \\
\hline & Conventional & 39 & $62 \pm 18$ & 52 & NA & $33 \pm 8$ & $37 \pm 6$ & $103 \pm 23$ & $36 \pm 6$ \\
\hline \multirow[t]{2}{*}{ Hilbert 2001} & NIV & 26 & $48 \pm 14$ & 69 & 58 & $45 \pm 10$ & $35 \pm 3$ & $141 \pm 24$ & $37 \pm 4$ \\
\hline & Conventional & 26 & $50 \pm 12$ & 73 & 58 & $42 \pm 9$ & $36 \pm 3$ & $136 \pm 23$ & $38 \pm 5$ \\
\hline \multirow[t]{2}{*}{ Antonelli 2000} & NIV & 16 & $45 \pm 19$ & 65 & 0 & NA & $38 \pm 3$ & NA & $42 \pm 10$ \\
\hline & Conventional & 15 & $44 \pm 10$ & 60 & 0 & NA & $37 \pm 1$ & NA & $38 \pm 9$ \\
\hline \multirow[t]{2}{*}{ Delclaux 2000} & NIV & 40 & $56(19-85)$ & 61 & NA & $32(6-87)$ & $34(20-60)$ & $140(59-288)$ & $36(26-66)$ \\
\hline & Conventional & 41 & $60(18-88)$ & 66 & NA & $32(6-102)$ & $32(12-52)$ & $148(62-283)$ & $35(22-47)$ \\
\hline \multirow{2}{*}{$\begin{array}{l}\text { Confalonieri } \\
1999\end{array}$} & NIV & 16 & $66 \pm 14$ & 82 & NA & NA & $37 \pm 5$ & $183 \pm 36$ & $50 \pm 21$ \\
\hline & Conventional & 17 & $61 \pm 21$ & 61 & NA & NA & $36 \pm 6$ & $167 \pm 47$ & $47 \pm 18$ \\
\hline \multirow[t]{2}{*}{ Wysocki 1993} & NIV & 14 & $64 \pm 18$ & 57 & NA & $17 \pm 7$ & $35 \pm 8$ & NA & $44 \pm 13$ \\
\hline & Conventional & 10 & $62 \pm 11$ & 60 & NA & $12 \pm 5$ & $35 \pm 8$ & NA & $42 \pm 14$ \\
\hline \multicolumn{10}{|c|}{$\begin{array}{l}\text { Data are presented as mean } \pm \text { SD or median (interquartile range) unless otherwise noted. } \\
\text { SAPS II score }=\text { Simplified Acute Physiology Score II }\end{array}$} \\
\hline
\end{tabular}

PEEP that ranges from $2-3 \mathrm{~cm} \mathrm{H}_{2} \mathrm{O}$, although this decreases with mouth opening. ${ }^{33,35}$

In our network meta-analysis, we found that the total intubation rate and short-term mortality rate were as high as $40 \%$ and $28 \%$, respectively, which is consistent with previous studies. 7,8,27,29,34,36,37 NIV was associated with significant reductions of intubation rates in comparison to conventional oxygen therapy group. The rates of shortand long-term morality were lower in the NIV group compared to other groups, but the difference didn't reach statistical significance. These findings are reliable because they are derived from a large patient population from 16 different RCTs. A few RCTs enrolled a small proportion of subjects with pulmonary edema as a cause of acute hypoxemic respiratory failure without reporting the outcomes in this subgroup of subjects. In our sensitivity analysis, which was performed by excluding these studies, ${ }^{17,19,22,30}$ we found that the rates of intubation remained significantly lower in the NIV group. Further well-controlled randomized trials that are conducted exclusively in subjects with de novo respiratory failure are needed to determine if the significant reduction in intubation and need for mechanical ventilation will translate into a mortality benefit. Furthermore, several risk factors are known to increase the risk of NIV failure, including high clinical severity scores, severe ARDS, older age, and pneumonia. Because we lacked subject-level data necessary to conduct a subgroup or 


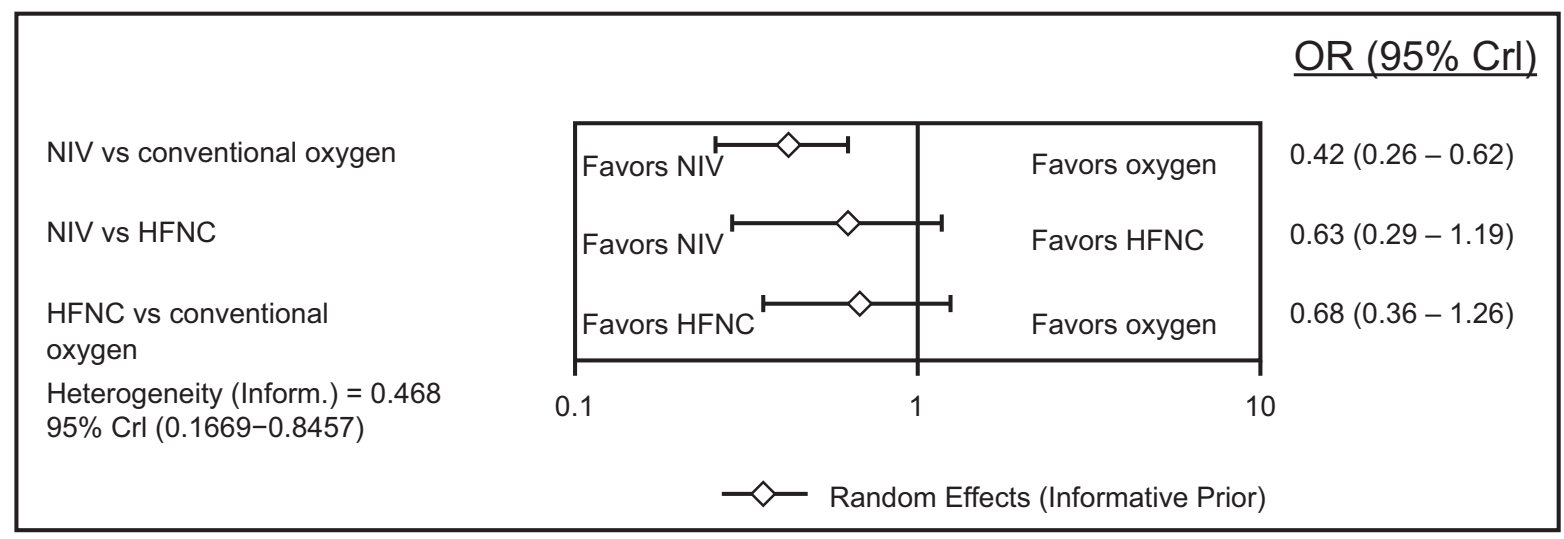

Fig. 3. Forest plots illustrating rate of intubation between the competing treatments. NIV = noninvasive ventilation; HFNC $=$ high-flow nasal cannula; $\mathrm{OR}=$ odds ratio; $\mathrm{Crl}=$ credible interval.

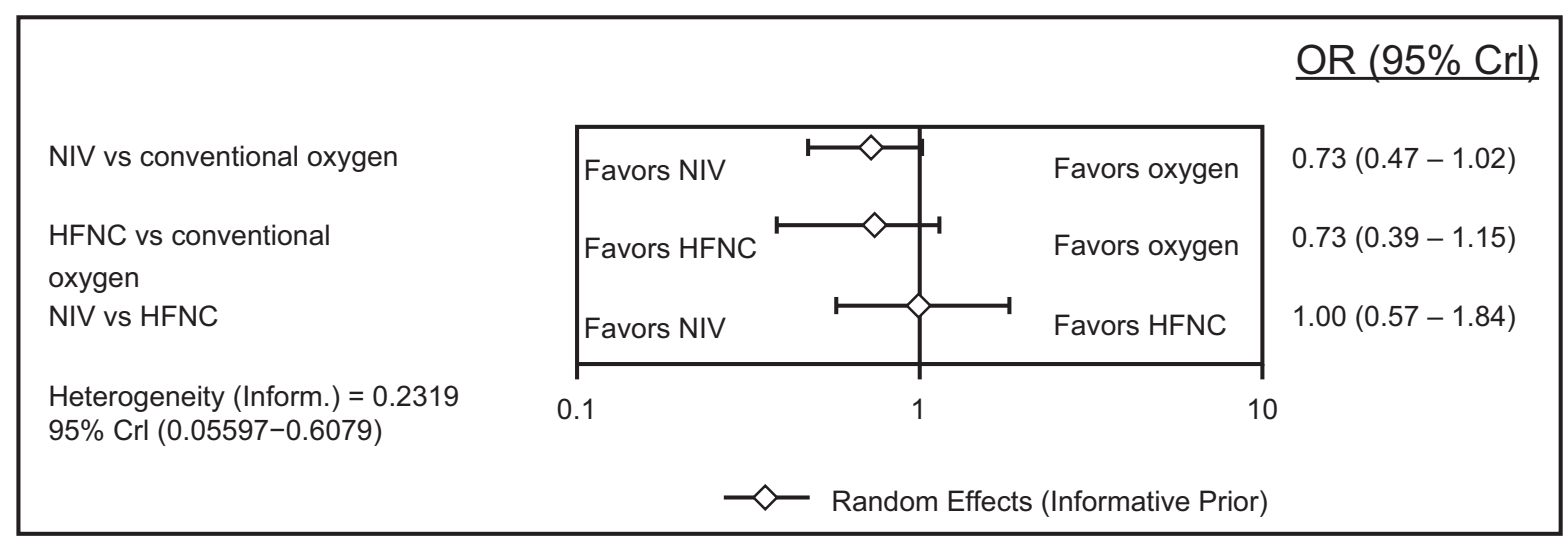

Fig. 4. Forest plots summarizing short-term all-cause mortality between the competing treatments. NIV = noninvasive ventilation; $\mathrm{HFNC}=$ high-flow nasal cannula; OR = odds ratio; $\mathrm{Crl}=$ credible interval.

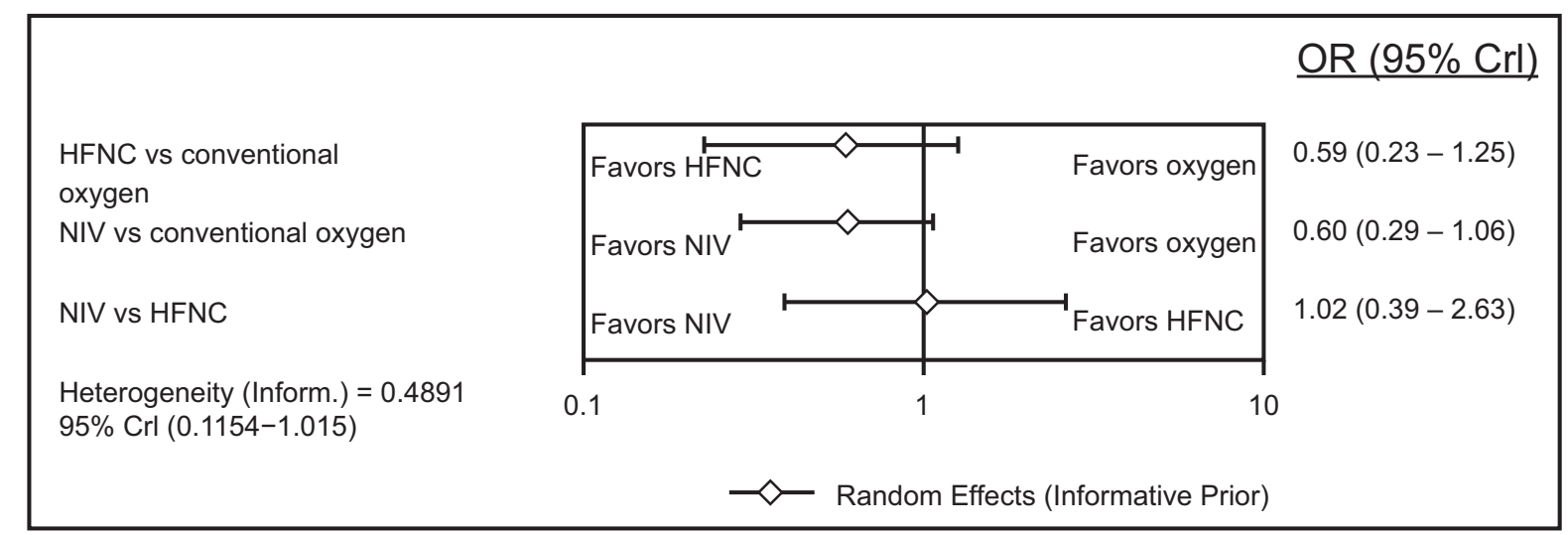

Fig. 5. Forest plots summarizing long-term all-cause mortality between the competing treatments. NIV = noninvasive ventilation; HFNC = highflow nasal cannula; $\mathrm{OR}$ = odds ratio; $\mathrm{Crl}=$ credible interval.

sensitivity analysis with control for these risk factors, they should be addressed in further studies.

A small number studies have conducted a direct comparison between HFNC and NIV or conventional oxygen therapy, and of those performed, results have been con- troversial. Frat et $\mathrm{al}^{5}$ conducted an RCT involving $>300$ subjects and found a mortality benefit with HFNC in comparison to NIV and conventional oxygen therapy, although there was no significant reduction in intubation rates, which was reduced significantly in subjects with 
$\mathrm{P}_{\mathrm{aO}_{2}} / \mathrm{F}_{\mathrm{IO}_{2}}<200$. However, a delay of intubation and high tidal-volume delivered $(>9 \mathrm{~mL} / \mathrm{kg}$ of ideal body weight) could have attributed to the higher intubation rate and increased mortality in the NIV group. ${ }^{31,38}$ In contrast, several subsequent trials in different patient populations found no difference between HFNC and NIV in intubation rates. ${ }^{18,19}$ In our network meta-analysis, we conducted direct and indirect comparisons between HFNC and NIV involving 1,168 subjects from the 16 included studies. Comparing HFNC and NIV, we found no significant difference in the need for intubation and invasive ventilation, nor any difference in short- or long-term mortality. Several pairwise meta-analyses with direct comparisons have reported similar results. ${ }^{14,39}$ Further well-controlled trials conducting head-to-head comparisons between these oxygenation strategies in subjects with de novo respiratory failure are needed to determine the superiority between HFNC and NIV while controlling for causes and severity of acute hypoxemic respiratory failure.

HFNC is a more comfortable means of respiratory support and is associated with more relief of dyspnea compared to conventional oxygen therapy, ${ }^{16,40}$ and HFNC is frequently used in patients with hypoxemic respiratory failure with $\mathrm{S}_{\mathrm{pO}_{2}}<90$ despite being treated with conventional oxygen therapy during postextubation respiratory failure and during intubation. ${ }^{11}$ In contrast to the trial by Frat et al, ${ }^{5}$ other trials found no difference between HFNC and conventional oxygen therapy in subjects with hypoxemic respiratory failure. ${ }^{12,16,17,40,41}$ However, HFNC showed superiority over conventional oxygen therapy in subjects with postextubation respiratory failure in terms of a reduction of intubation rates..$^{42,43}$ Additionally, HFNC is associated with a significantly higher lowest $\mathrm{S}_{\mathrm{pO}_{2}}$ when used during intubation. ${ }^{44}$ In our pooled analysis, HFNC was not superior to conventional oxygen therapy with regard to reduction of intubation rates, short-term mortality, or long-term mortality among subjects with de novo respiratory failure. Our findings remained consistent because this direct metaanalysis was performed only between these interventions. Although our analysis included only subjects with de novo respiratory failure, inconsistent results were reported with previous meta-analyses that included subjects with different causes of acute hypoxemic respiratory failure, including postoperative and postextubation respiratory failure. ${ }^{9,39,45}$ Furthermore, unlike the NIV and conventional oxygen therapy groups, large proportions of subjects treated with HFNC in our analysis were immunocompromised, which may underestimate the benefit of HFNC because immunocompromised patients are often less stable and have greater comorbidities. Further studies are needed to identify patients who would receive the greatest benefit from this new oxygenation modality, while also assessing different causes of acute hypoxemic respiratory failure and other risk factors.
Our results are similar to a previous meta-analysis ${ }^{46}$ that showed no difference between HFNC when compared to NIV or conventional oxygen in subjects with hypoxemic respiratory failure. However, this earlier review included subjects with postoperative respiratory failure and subjects treated in the emergency department. Our results contradict a recently published meta-analysis ${ }^{47}$ which reported that HFNC was associated with a reduction of intubation rates but not with any mortality benefit when compared to conventional oxygen. However, the included studies investigated subjects with acute hypoxemic respiratory failure secondary to any cause in the ICU and the emergency department. Our meta-analysis included larger patient populations from RCTs that were conducted only in the ICU and in subjects with hypoxemic respiratory failure excluding patients with COPD, cardiogenic pulmonary edema, postoperative respiratory failure, and postextubation respiratory failure. Furthermore, our results and conclusions were drawn from performing a network meta-analysis with direct and indirect analysis between the competing interventions. Additionally, we were able to conduct a comparison between HFNC and NIV despite the fact that few studies have conducted direct comparisons between these interventions.

Our analysis has several limitations. First, there were fewer subjects treated with HFNC in comparison to other competing interventions. Second, a large proportion of subjects treated with HFNC were immunocompromised. Third, there was a lack of studies that conducted direct comparison between HFNC and other oxygenation modalities in acute de novo hypoxemic respiratory failure. Fourth, blinding for the intervention for participants and personnel was impossible given the nature of the intervention, which could introduce bias. Fifth, NIV was delivered for different durations and with different settings. Finally, because we lacked subject-level data, we were unable to perform subgroup analysis based on severity and different reasons for respiratory failure.

\section{Conclusion}

Among subjects with de novo hypoxemic respiratory failure, noninvasive ventilation was associated with a significant reduction in intubation rates but not with a significant reduction in short- or long-term mortality when compared with conventional oxygen therapy. Additionally, there was no significant difference between noninvasive ventilation and HFNC therapy regarding the primary and secondary outcomes. Similarly, we found HFNC to have no benefit in reducing intubation rates or mortality when compared to conventional oxygen therapy. Further RCTs conducting head-to-head comparisons between HFNC and NIV, while also controlling for risk factors such as clinical 


\section{Oxygenation in De Novo Acute Hypoxemic Respiratory Failure}

severity scores, various etiologies of respiratory failure, and age, are needed.

\section{REFERENCES}

1. Rochwerg B, Brochard L, Elliott MW, Hess D, Hill NS, Nava S, et al. Official ERS/ATS clinical practice guidelines: noninvasive ventilation for acute respiratory failure. Eur Respir J 2017;50(2): 1602426 .

2. Lightowler JV, Wedzicha JA, Elliott MW, Ram FSF. Non-invasive positive pressure ventilation to treat respiratory failure resulting from exacerbations of chronic obstructive pulmonary disease: Cochrane systematic review and meta-analysis. BMJ 2003;326(7382):185-185.

3. Keenan SP, Sinuff T, Cook DJ, Hill NS. Which patients with acute exacerbation of chronic obstructive pulmonary disease benefit from noninvasive positive-pressure ventilation? A systematic review of the literature. Ann Intern Med 2003;138(11):861-870.

4. Brochard L, Mancebo J, Wysocki M, Lofaso F, Conti G, Rauss A, et al. Noninvasive ventilation for acute exacerbations of chronic obstructive pulmonary disease. N Engl J Med 1995;333(13):817822.

5. Frat JP, Thille AW, Mercat A, Girault C, Ragot S, Perbet S, et al. High-flow oxygen through nasal cannula in acute hypoxemic respiratory failure. N Engl J Med 2015;372(23):2185-2196.

6. Brambilla AM, Aliberti S, Prina E, Nicoli F, Del Forno M, Nava S, et al. Helmet CPAP vs. oxygen therapy in severe hypoxemic respiratory failure due to pneumonia. Intensive Care Med 2014;40(7): 942-949.

7. Delclaux C, L'Her E, Alberti C, Mancebo J, Abroug F, Conti G, et al. Treatment of acute hypoxemic nonhypercapnic respiratory insufficiency with continuous positive airway pressure delivered by a face mask: a randomized controlled trial. JAMA 2000;284(18):23522360.

8. Confalonieri M, Potena A, Carbone G, Porta RD, Tolley EA, Umberto Meduri G. Acute respiratory failure in patients with severe community-acquired pneumonia. A prospective randomized evaluation of noninvasive ventilation. Am J Respir Crit Care Med 1999; 160(5 Pt 1):1585-1591.

9. Xu XP, Zhang XC, Hu SL, Xu JY, Xie JF, Liu SQ, et al. Noninvasive ventilation in acute hypoxemic nonhypercapnic respiratory failure: a systematic review and meta-analysis. Crit Care Med 2017; 45(7): e727-e733.

10. Xu X, Yuan B, Liang Q, Hu J, Shi Z, Huang H, et al. Noninvasive ventilation for acute lung injury a meta-analysis of randomized controlled trials. Heart Lung 2017;45(3):249-257.

11. Frat J-P, Coudroy R, Thille AW. Non-invasive ventilation or highflow oxygen therapy: When to choose one over the other? Respirology 2019;24(8):724-731.

12. Azoulay E, Lemiale V, Mokart D, Nseir S, Argaud L, Pène F, et al. Effect of high-flow nasal oxygen vs standard oxygen on 28-day mortality in immunocompromised patients with acute respiratory failure: the HIGH randomized clinical trial. JAMA 2018;320(20): 2099-2107.

13. Leeies M, Flynn E, Turgeon AF, Paunovic B, Loewen H, Rabbani R, et al. High-flow oxygen via nasal cannulae in patients with acute hypoxemic respiratory failure: a systematic review and meta-analysis. Syst Rev 2017;6(1):202-202.

14. Zhu Y, Yin H, Zhang R, Wei J. High-flow nasal cannula oxygen therapy versus conventional oxygen therapy in patients with acute respiratory failure: a systematic review and meta-analysis of randomized controlled trials. BMC Pulm Med 2017;17(1):201.

15. Lin SM, Liu KX, Lin ZH, Lin PH. Does high-flow nasal cannula oxygen improve outcome in acute hypoxemic respiratory failure? A systematic review and meta-analysis. Respir Med 2017;131:58-64.
16. Jones PG, Kamona S, Doran O, Sawtell F, Wilsher M. Randomized controlled trial of humidified high-flow nasal oxygen for acute respiratory distress in the emergency department: the HOT-ER study. Respir Care 2016;61(3):291-299.

17. Lemiale V, Mokart D, Mayaux J, Lambert J, Rabbat A, Demoule A, et al. The effects of a 2-h trial of high-flow oxygen by nasal cannula versus Venturi mask in immunocompromised patients with hypoxemic acute respiratory failure: a multicenter randomized trial. Crit Care 2015;19:380-380.

18. Stéphan F, Barrucand B, Petit P, Rézaiguia-Delclaux S, Médard A, Delannoy B, et al. High-flow nasal oxygen vs noninvasive positive airway pressure in hypoxemic patients after cardiothoracic surgery: a randomized clinical trial. JAMA 2015;313(23):2331-2339.

19. Azevedo JR, Montenegro WS, Leitao AL, Silva MM, Prazeres JS, Maranhao JP. High flow nasal cannula oxygen (HFNC) versus noninvasive positive pressure ventilation (NIPPV) in acute hypoxemic respiratory failure. A pilot randomized controlled trial. Intensive Care Med Exp 2015;3(Suppl 1):A166.

20. Moher D, Shamseer L, Clarke M, Ghersi D, Liberati A, Petticrew M, et al. Preferred reporting items for systematic review and metaanalysis protocols (PRISMA-P) 2015 statement. Syst Rev 2015;4: $1-1$.

21. Cortegiani A, Crimi C, Sanfilippo F, Noto A, Di Falco D, Grasselli $\mathrm{G}$, et al. High flow nasal therapy in immunocompromised patients with acute respiratory failure: A systematic review and meta-analysis. J Crit Care 2019;50:250-256.

22. Lemiale V, Mokart D, Resche-Rigon M, Pène F, Mayaux J, Faucher $\mathrm{E}$, et al. Effect of noninvasive ventilation vs oxygen therapy on mortality among immunocompromised patients with acute respiratory failure: a randomized clinical trial. JAMA 2015;314(16):17111719.

23. Wermke M, Schiemanck S, Höffken G, Ehninger G, Bornhäuser M, Illmer T. Respiratory failure in patients undergoing allogeneic hematopoietic SCT-a randomized trial on early non-invasive ventilation based on standard care hematology wards. Bone Marrow Transplant 2012;47(4):574-580.

24. Zhan Q, Sun B, Liang L, Yan X, Zhang L, Yang J, et al. Early use of noninvasive positive pressure ventilation for acute lung injury: a multicenter randomized controlled trial. Crit Care Med 2012;40(2): 455-460.

25. Cosentini R, Brambilla AM, Aliberti S, Bignamini A, Nava S, Maffei A, et al. Helmet continuous positive airway pressure vs oxygen therapy to improve oxygenation in community-acquired pneumonia: a randomized, controlled trial. Chest 2010;138(1):114-120.

26. Squadrone V, Massaia M, Bruno B, Marmont F, Falda M, Bagna C, et al. Early CPAP prevents evolution of acute lung injury in patients with hematologic malignancy. Intensive Care Med 2010;36(10):16661674.

27. Ferrer M, Esquinas A, Leon M, Gonzalez G, Alarcon A, Torres A. Noninvasive ventilation in severe hypoxemic respiratory failure: a randomized clinical trial. Am J Respir Crit Care Med 2003;168(12): 1438-1444.

28. Hilbert G, Gruson D, Vargas F, Valentino R, Gbikpi-Benissan G, Dupon M, et al. Noninvasive ventilation in immunosuppressed patients with pulmonary infiltrates, fever, and acute respiratory failure. N Engl J Med 2001;344(7):481-487.

29. Antonelli M, Conti G, Bufi M, Costa MG, Lappa A, Rocco M, et al. Noninvasive ventilation for treatment of acute respiratory failure in patients undergoing solid organ transplantation: a randomized trial. JAMA 2000;283(2):235-241.

30. Wysocki M, Tric L, Wolff MA, Gertner J, Millet H, Herman B. Noninvasive pressure support ventilation in patients with acute respiratory failure. Chest 1993;103(3):907-913. 


\section{Oxygenation in De Novo Acute Hypoxemic Respiratory Failure}

31. Carteaux G, Millán-Guilarte T, De Prost N, Razazi K, Abid S, Thille $\mathrm{AW}$, et al. Failure of noninvasive ventilation for de novo acute hypoxemic respiratory failure: role of tidal volume. Crit Care Med 2016;44(2):282-290.

32. Kallet RH, Diaz JV. The physiologic effects of noninvasive ventilation. Respir Care 2009;54(1):102-115.

33. Mauri T, Turrini C, Eronia N, Grasselli G, Volta CA, Bellani G, et al. Physiologic Effects of High-Flow Nasal Cannula in Acute Hypoxemic Respiratory Failure. Am J Respir Crit Care Med 2017; 195(9):1207-1215.

34. Martin TJ, Hovis JD, Costantino JP, Bierman MI, Donahoe MP, Rogers RM, et al. A randomized, prospective evaluation of noninvasive ventilation for acute respiratory failure. Am J Respir Crit Care Med 2000;161(3 Pt 1):807-813.

35. Corley A, Caruana LR, Barnett AG, Tronstad O, Fraser JF. Oxygen delivery through high-flow nasal cannulae increase end-expiratory lung volume and reduce respiratory rate in post-cardiac surgical patients. Br J Anaesth 2011;107(6):998-1004.

36. Thille AW, Contou D, Fragnoli C, Córdoba-Izquierdo A, Boissier F, Brun-Buisson C. Non-invasive ventilation for acute hypoxemic respiratory failure: intubation rate and risk factors. Crit Care 2013; 17(6):R269-R269.

37. Carrillo A, Gonzalez-Diaz G, Ferrer M, Martinez-Quintana ME, Lopez-Martinez A, Llamas N, et al. Non-invasive ventilation in community-acquired pneumonia and severe acute respiratory failure. Intensive Care Med 2012;38(3):458-466.

38. Slutsky AS, Ranieri VM. Ventilator-induced lung injury. N Engl J Med 2014;370(10):980-980.

39. Zhao H, Wang H, Sun F, Lyu S, An Y. High-flow nasal cannula oxygen therapy is superior to conventional oxygen therapy but not to noninvasive mechanical ventilation on intubation rate: a systematic review and meta-analysis. Crit Care 2017;21(1):184-184.

40. Rittayamai N, Tscheikuna J, Rujiwit P. High-flow nasal cannula versus conventional oxygen therapy after endotracheal extubation: a randomized crossover physiologic study. Respir Care 2014;59(4): 485-490.

41. Frat J-P, Ragot S, Girault C, Perbet S, Prat G, Boulain T, et al. Effect of non-invasive oxygenation strategies in immunocompromised patients with severe acute respiratory failure: a post-hoc analysis of a randomised trial. Lancet Respir Med 2016;4(8):646-652.

42. Hernández G, Vaquero C, González P, Subira C, Frutos-Vivar F, Rialp G, et al. Effect of Postextubation High-Flow Nasal Cannula vs Conventional Oxygen Therapy on Reintubation in Low-Risk Patients: A Randomized Clinical Trial. JAMA 2016;315(13):1354-1361.

43. Maggiore SM, Idone FA, Vaschetto R, Festa R, Cataldo A, Antonicelli $\mathrm{F}$, et al. Nasal high-flow versus Venturi mask oxygen therapy after extubation. Effects on oxygenation, comfort, and clinical outcome. Am J Respir Crit Care Med 2014;190(3):282-288.

44. Miguel-Montanes R, Hajage D, Messika J, Bertrand F, Gaudry S, Rafat $\mathrm{C}$, et al. Use of high-flow nasal cannula oxygen therapy to prevent desaturation during tracheal intubation of intensive care patients with mild-to-moderate hypoxemia. Crit Care Med 2015;43(3): 574-583.

45. Monro-Somerville T, Sim M, Ruddy J, Vilas M, Gillies MA. The Effect of High-Flow Nasal Cannula Oxygen Therapy on Mortality and Intubation Rate in Acute Respiratory Failure: A Systematic Review and Meta-Analysis. Crit Care Med 2017;45(4):e449-e456.

46. Maitra S, Som A, Bhattacharjee S, Arora MK, Baidya DK. Comparison of high-flow nasal oxygen therapy with conventional oxygen therapy and noninvasive ventilation in adult patients with acute hypoxemic respiratory failure: A meta-analysis and systematic review. J Crit Care 2016;35:138-144.

47. Rochwerg B, Granton D, Wang DX, Helviz Y, Einav S, Frat JP, et al. High flow nasal cannula compared with conventional oxygen therapy for acute hypoxemic respiratory failure: a systematic review and meta-analysis. Intensive Care Med 2019 Mar 19. doi: 10.1007/ s00134-019-05590-5. 